\title{
Use of interfacial layers to prolong hole lifetimes in hematite probed by ultrafast transient absorption spectroscopy
}

\author{
Alexander T. Paradzaha, ${ }^{\mathrm{a}, *}$,Mmantsae Diale ${ }^{\mathrm{a}}$, Kelebogile Maabong, ${ }^{\mathrm{a}, \mathrm{b}}$, Tjaart P. J. Krüger ${ }^{\mathrm{a}, * *}$ \\ ${ }^{a}$ Department of Physics, University of Pretoria, Private Bag X20, Hatfield 0028, South Africa \\ $b$ Department of Physics, University of Botswana, Private Bag 0022, Gaborone, Botswana
}

\begin{abstract}
Hematite is a widely investigated material for applications in solar water oxidation due primarily to its small bandgap. However, full realization of the material continues to be hampered by fast electron-hole recombination rates among other weaknesses such as low hole mobility, short hole diffusion length and low conductivity. To address the problem of fast electron-hole recombination, researchers have resorted to growth of nano-structured hematite, doping and use of under-layers. Under-layer materials enhance the photo-current by minimising electron-hole recombination through suppressing of back electron flow from the substrate, such as fluorine-doped tin oxide (FTO), to hematite. We have carried out ultrafast transient absorption spectroscopy on hematite in which $\mathrm{Nb}_{2} \mathrm{O}_{5}$ and $\mathrm{SnO}_{2}$ materials were used as interfacial layers to enhance hole lifetimes. The transient absorption data was fit with four different lifetimes ranging from a few hundred femtoseconds to a few nanoseconds. We show that the electron-hole recombination is slower in samples where interfacial layers are used than in pristine hematite. We also develop a model through target analysis to illustrate the effect of under-layers on electron-hole recombination rates in hematite thin films.
\end{abstract}

Keywords: hematite, ultrafast pump-probe spectroscopy, under-layer materials, $\mathrm{Nb}_{2} \mathrm{O}_{5}, \mathrm{SnO}_{2}$

\section{Introduction}

Economic growth, especially in developing countries, and expanding world populations are the two main reasons for increasing world energy consumption. The need for more energy has inevitably led to increased burning of fossil fuels leading to environmental problems, particularly global warming. World energy consumption will most certainly increase each year, hence the need for cleaner energy. While the total global power demand is currently $\sim 15 \mathrm{TW}$ [1] the total solar power of $\sim 10^{4} \mathrm{TW}$ irradiating the earth's surface far exceeds our demands by nearly three orders of magnitude[2]. It is therefore imperative that efficient ways of harnessing and storing solar energy have to be utilized in addition to other renewable energy sources such as wind, geothermal, biomass and hydropower. In recent years, research has focussed on the use of

\footnotetext{
${ }^{*}$ Corresponding author

** Corresponding author

Email addresses: paradzah.alex@gmail.com (Alexander T. Paradzah), tjaart.kruger@up.ac.za (Tjaart P. J. Krüger)
} 
semiconductors as electrodes for photoelectrochemical water splitting to produce oxygen $\left(\mathrm{O}_{2}\right)$ and hydrogen $\left(\mathrm{H}_{2}\right)$ as fuels.

Hematite $\left(\alpha-\mathrm{Fe}_{2} \mathrm{O}_{3}\right)$ has become a subject of renewed interest in recent years owing to its suitability for use in water splitting. $\alpha-\mathrm{Fe}_{2} \mathrm{O}_{3}$ has a small bandgap of $\sim 2.1 \mathrm{eV}$ that enables absorption in the visible region of the solar spectrum, making it a much more appropriate material compared to other photoactive semiconductors such as titanium dioxide $\left(\mathrm{TiO}_{2}\right)$, tungsten trioxide $\left(\mathrm{WO}_{3}\right)$, bismuth vanadate $\left(\mathrm{BiVO}_{4}\right)$ and zinc oxide $(\mathrm{ZnO})[3[5]$. Besides an ideal bandgap, hematite has other attractive properties, which include its abundance, low production cost, great stability under aqueous conditions, non-toxicity and a high theoretical conversion efficiency of up to $16.8 \%[6]$. While $\alpha$ - $\mathrm{Fe}_{2} \mathrm{O}_{3}$ has mostly attractive properties as far as water splitting goes, it however also has some shortcomings, most notably being a short hole diffusion length of about $2-4 \mathrm{~nm}$ [10 12 and long photon penetration lengths [13 15]. These shortcomings ultimately lead to very fast charge carrier recombination rates, thus hampering the full realization of the material in water oxidation. To address these problems in $\alpha-\mathrm{Fe}_{2} \mathrm{O}_{3}$, scientists have considered either elemental doping [16 19], growing of nanostructured hematite [20 22] or use of host-guest heterostructures [7, 23, 24]. Elemental doping increases the free charge carrier concentration, improves the surface properties and can also be used to alter the bandgap of semiconductors in a way that favours light absorption and limits recombination. Use of nanostructures, on the other hand, minimises the distance photo-created holes travel to the semiconductor/electrolyte interface where the process of water splitting occurs.

The host-guest approach has been proven to significantly improve photocurrent in hematite electrodes with the use of materials such as silicon dioxide $\left(\mathrm{SiO}_{2}\right)$ [25, niobium oxide $\left(\mathrm{Nb}_{2} \mathrm{O}_{5}\right)$ [9, 14, tin dioxide $\left(\mathrm{SnO}_{2}\right)$ [11, $\mathrm{TiO}_{2}$ [26] and gallium oxide $\left(\mathrm{Ga}_{2} \mathrm{O}_{3}\right)$ [27] used as host (or under-layer) materials. Host materials improve PEC efficiency by increasing the charge carrier concentration through diffusion doping and by suppressing electron recombination at the fluorine-doped tin oxide (FTO) / hematite interface, thereby increasing the hole lifetimes [24, 25]. Under-layers also improve the material photo-activity by improving the crystallinity (and interfacial properties) as well as supplementing the absorption region (if well chosen) of the guest material [24. Several studies have been carried out in recent years to illustrate the effect of under-layers, particurlarly showing improved photoelectrochemical (PEC) performance. In this study, we use femtosecond pump-probe spectroscopy to monitor changes in the electron-hole recombination rates resulting from using $\mathrm{SnO}_{2}$ and $\mathrm{Nb}_{2} \mathrm{O}_{5}$ as under-layers for hematite. No study has yet been carried out to illustrate the effect of under-layers on recombination dynamics in hematite nanostructures at an ultrafast scale. This study therefore brings an extra dimension in the understanding of the effect of under-layers in enhancing photocurrent.

\section{Experimental}

\subsection{Materials}

Measurements were carried out on thin films of pristine $\alpha-\mathrm{Fe}_{2} \mathrm{O}_{3}, \mathrm{Nb}_{2} \mathrm{O}_{5} / \alpha-\mathrm{Fe}_{2} \mathrm{O}_{3}$ and $\mathrm{SnO}_{2} / \alpha-\mathrm{Fe}_{2} \mathrm{O}_{3}$ heterostructures . Materials were deposited on clean, transparent FTO substrates, cleaned as previously 
reported 28]. $\mathrm{Nb}_{2} \mathrm{O}_{5}$ under-layer precursor was prepared by dissolving diethanolamine in ethanol and adding niobium ethoxide to the solution while stirring. The solution was then stirred for a further 1 hour at room temperature to give the final precursor. The $\mathrm{SnO}_{2}$ precursor was prepared by dissolving Tin(II) chloride hydrate in ethanol and the solution was stirred for 1 hour at room temperature. The precursors were then spin coated onto FTO substrates at $5000 \mathrm{rpm}$ to give a layer thickness of $\sim 40 \mathrm{~nm}$. The resulting films were annealed at $500{ }^{\circ} \mathrm{C}$ for 45 minutes. $\alpha-\mathrm{Fe}_{2} \mathrm{O}_{3}$ thin films were then deposited onto the under-layers and also on bare FTO for control. The precursor for $\alpha-\mathrm{Fe}_{2} \mathrm{O}_{3}$ was prepared as previously reported [28. Spin coating for the hematite layer was performed at $4000 \mathrm{rpm}$ to obtain a layer that is $\sim 60 \mathrm{~nm}$ thick. The films were then annealed in air for 1 hour at $500{ }^{\circ} \mathrm{C}$. A schematic of the preparation steps is shown in Figure 1 Thin film compositions were confirmed using XRD spectroscopy.

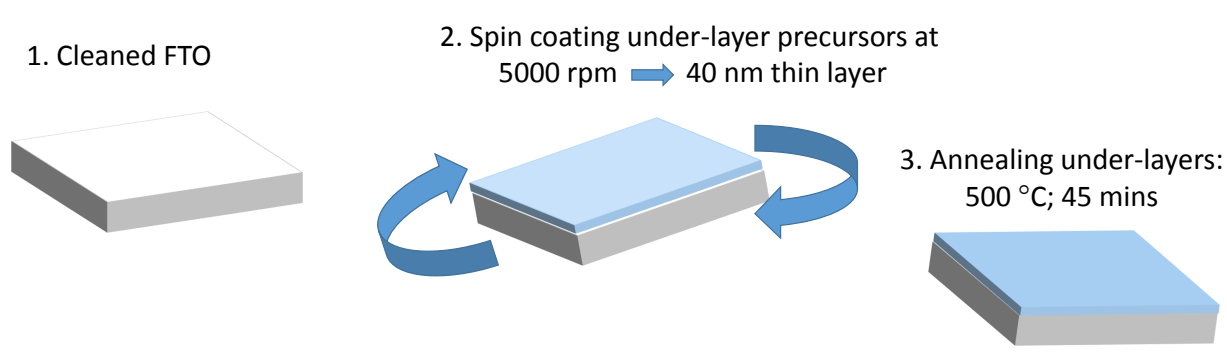

$$
\begin{array}{cc}
\text { 5. Annealing thin films: } & \text { 4. Spin coating iron-oleate } \\
500^{\circ} \mathrm{C} ; 1 \text { hour } & \text { (onto under-layers and on bare FTO) at } \\
4000 \mathrm{rpm} \Rightarrow 60 \mathrm{~nm} \text { thin layer }
\end{array}
$$
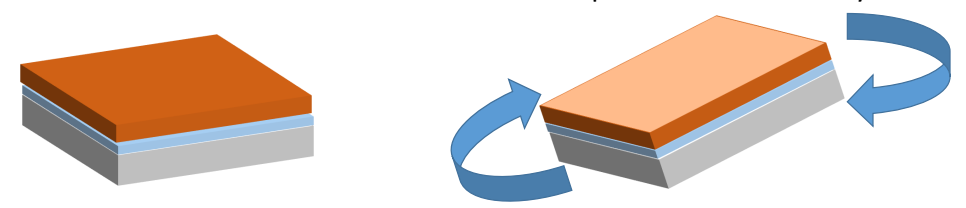

Figure 1: Schematic diagram showing major steps of the under-layers and hematite thin films deposition on FTO by spin coating.

\subsection{Experimental Methods}

The absorbance of hematite thin films was measured using an Ocean Optics spectrometer (USB400 series). Transient absorption spectroscopy measurements were performed using a home-built experimental setup, with a Ti:Sapphire amplified laser source (150 fs pulse duration; $775 \mathrm{~nm}$ peak wavelength; $1 \mathrm{kHz}$ repetition rate, Clark-MXR 2110i). An output averaging $850 \mathrm{~mW}$ was split into two beams, $\sim 255 \mathrm{~mW}$ for the pump beam and $\sim 595 \mathrm{~mW}$ for the probe. The pump beam was directed into a beta barium borate (BBO) crystal for frequency doubling to produce a $387.5 \mathrm{~nm}$ centred beam with a FWHM bandwidth of 4 $\mathrm{nm}$. The phase matching angle of the BBO crystal was tuned to get an output of $25 \mathrm{~mW}$, which was then focussed into the sample using a telescope. Pump-probe measurements give difference absorption $(\Delta \mathrm{A}=$ $\left.\mathrm{A}_{\text {pumped }}-\mathrm{A}_{\text {unpumped }}\right)$ spectra. A chopper was used in the pump beam path to enable pump on and pump off data collection. The pulse duration of the $775 \mathrm{~nm}$ beam directly from the laser was measured using a 
home-built frequency resolved optical gating set-up and found to be $150 \mathrm{fs}$, and we estimate the duration of the $387.5 \mathrm{~nm}$ pump beam just before the sample to be $200 \mathrm{fs}$. The probe beam was passed through a 2 ns optical delay line. From the delay line we focussed the probe beam into a sapphire crystal to produce a white light continuum in the wavelength range from 430 to $680 \mathrm{~nm}$. A beam splitter was used to split the white light continuum into probe and reference beams. The reference beam is important to account for fluctuations that might arise in the laser output and generally also for noise cancelling. The probe beam was focussed and made to overlap spatially and temporally with the pump beam inside the sample, while the reference was also focussed into the sample but without overlapping with the pump. Beyond the sample a pinhole was used to block the pump beam while the probe and reference beams were focussed into optical fibres onto a grating, which disperses the beams onto a photo-diode array. Initial processing of the data was done using ExciPro software to give out $\Delta \mathrm{A}$ spectra. Analysis of the obtained data was performed using Glotaran software [29] to extract recombination rates and decay lifetimes.

\section{Results and Discussion}

\subsection{Absorption}

Absorption measurements obtained for the three samples in the $375-875 \mathrm{~nm}$ wavelength region are shown in Figure 22 We normalized the absorption spectra of the three samples to enable better comparison of the spectral features. We observe uniform absorption features across all samples. This shows that the materials used as under-layers in this work do not significantly modify the absorption properties of hematite. Both $\mathrm{SnO}_{2}$ and $\mathrm{Nb}_{2} \mathrm{O}_{5}$ are transparent materials in the visible region due to wide bandgaps, i.e., the materials do not absorb photons in the visible spectrum. The bandgap of pure $\mathrm{Nb}_{2} \mathrm{O}_{5}$ is $\sim 3.4 \mathrm{eV}$ [30, 31], thus the contribution of this material to the absorption of hematite can only be observed at wavelengths below 365 nm. $\mathrm{SnO}_{2}$ has a bandgap value around $3.62 \mathrm{eV}(342.5 \mathrm{~nm})$ [32 34 and so its absorption contribution can only be noticeable at wavelengths below $343 \mathrm{~nm}$. The absorption maximum around $400 \mathrm{~nm}$ is believed to be a result of ligand to metal charge transfer (LMCT) from $\mathrm{O}(2 \mathrm{p})$ orbitals to $\mathrm{Fe}^{3+} 2 \mathrm{t}_{2 g}$ and $3 \mathrm{e}_{g}$ orbitals [3538. Absorption at wavelengths above $400 \mathrm{~nm}$ is attributed mainly to Fe d-d ligand field spin-flip transitions [35, 36]. The $\mathrm{d}-\mathrm{d}$ transitions are spin-forbidden [39, hence contribute only weak absorption features. The long tail extending beyond $800 \mathrm{~nm}$ indicates the presence of electronic states within the bandgap. These states could be $\mathrm{Nb}^{3+}$ and $\mathrm{Sn}^{2+}$ arising from substitution of $\mathrm{Fe}^{2+}$ in samples where $\mathrm{Nb}_{2} \mathrm{O}_{5}$ and $\mathrm{SnO}_{2}$ are used, respectively. Pristine $\alpha-\mathrm{Fe}_{2} \mathrm{O}_{3}$ also contains impurities within the bandgap, generally referred to as mid-gap states, and these can additionally contribute to absorption in the low energy region, above $800 \mathrm{~nm}$.

\subsection{Transient absorption spectroscopy}

Three-dimensional spectral evolution plots for the data obtained from the pump-probe measurements are shown in Figure $3 \mathrm{a}-3 \mathrm{c}$ and the corresponding difference absorption $(\Delta \mathrm{A})$ spectra at selected delay times 


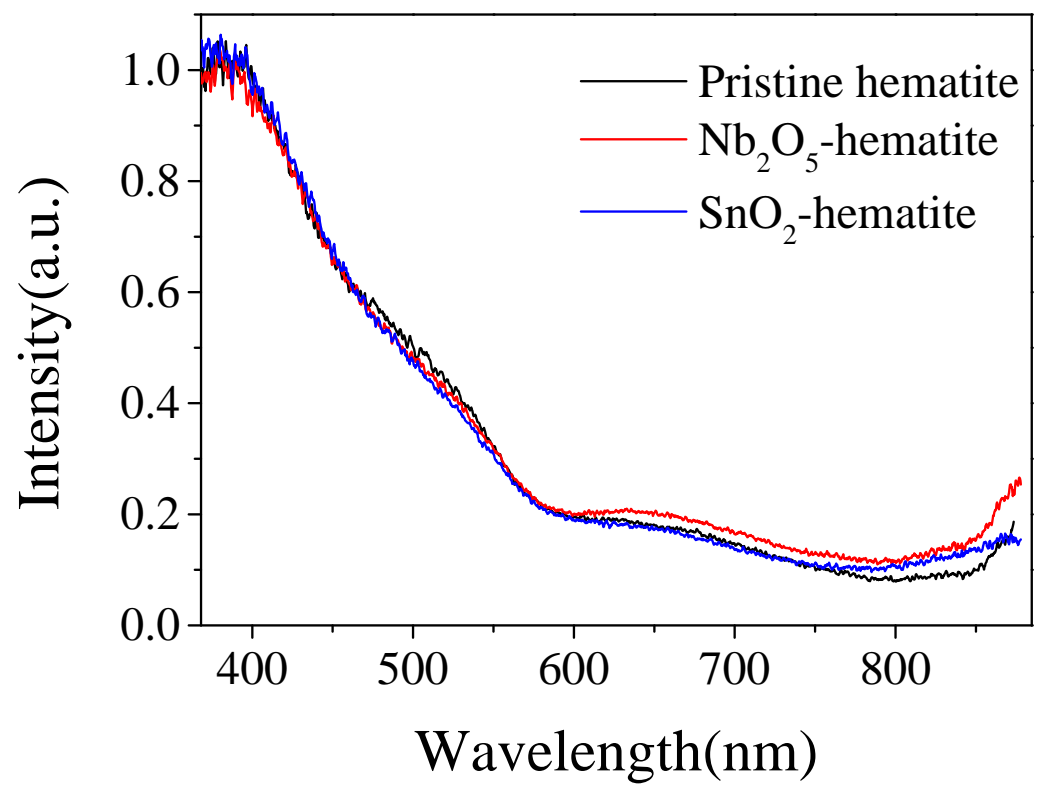

Figure 2: Normalized absorption spectra for Pristine hematite, $\mathrm{Nb}_{2} \mathrm{O}_{5}$-hematite and $\mathrm{SnO}_{2}$-hematite samples

from 0 ps to 1014 ps are shown in Figure $3 \mathrm{~d}-3 \mathrm{f}$. As in the case of the absorption spectra, there are no major differences in the spectroscopic features of the $\Delta \mathrm{A}$ spectra across the three samples. For all three samples we observe a bleach in the $\Delta \mathrm{A}$ signal below $\sim 450 \mathrm{~nm}(2.92 \mathrm{eV})$ and a broad ESA signal that peaks near $570 \mathrm{~nm}(2.18 \mathrm{eV})$ and extends beyond $650 \mathrm{~nm}$ ( above $1.91 \mathrm{eV}$ ). The region between $455 \mathrm{~nm}(2.72 \mathrm{eV})$ and $515 \mathrm{~nm}(2.41 \mathrm{eV})$ is also marked with a small ESA feature. Since the pump is centred at $387.5 \mathrm{~nm}(3.20 \mathrm{eV})$ with a FWHM bandwidth of only $4 \mathrm{~nm}$, the bleach observed below $\sim 480 \mathrm{~nm}$ is likely a result of stimulated emission (SE) rather than simply a reduction in absorption due to depletion of ground state molecules. SE signals are generally red-shifted since electrons undergo cooling to the conduction band minimum before SE occurs. The ESA feature around $570 \mathrm{~nm}$ is the main spectroscopic feature in hematite samples and has been attributed to absorption of photo-generated holes [5, 40, while the broad ESA tail beyond $600 \mathrm{~nm}$ is a result of the absorption of conduction band electrons [5].

\subsubsection{Global analysis}

To extract the different decay and recombination rates, we analysed the data using a four component sequential global analysis model as described in reference [29, 41. The four components used were decided upon following careful inspection of the singular value decomposition (SVD) parameters of the raw data. In each of the three cases, a very fast initial component was observed within $114-178$ fs. This initial component is attributed to hole cooling to the top of the valence band and electron cooling to the conduction band minimum. The second decay lifetimes are in the range of 1.43-1.55 ps and these are attributed to 

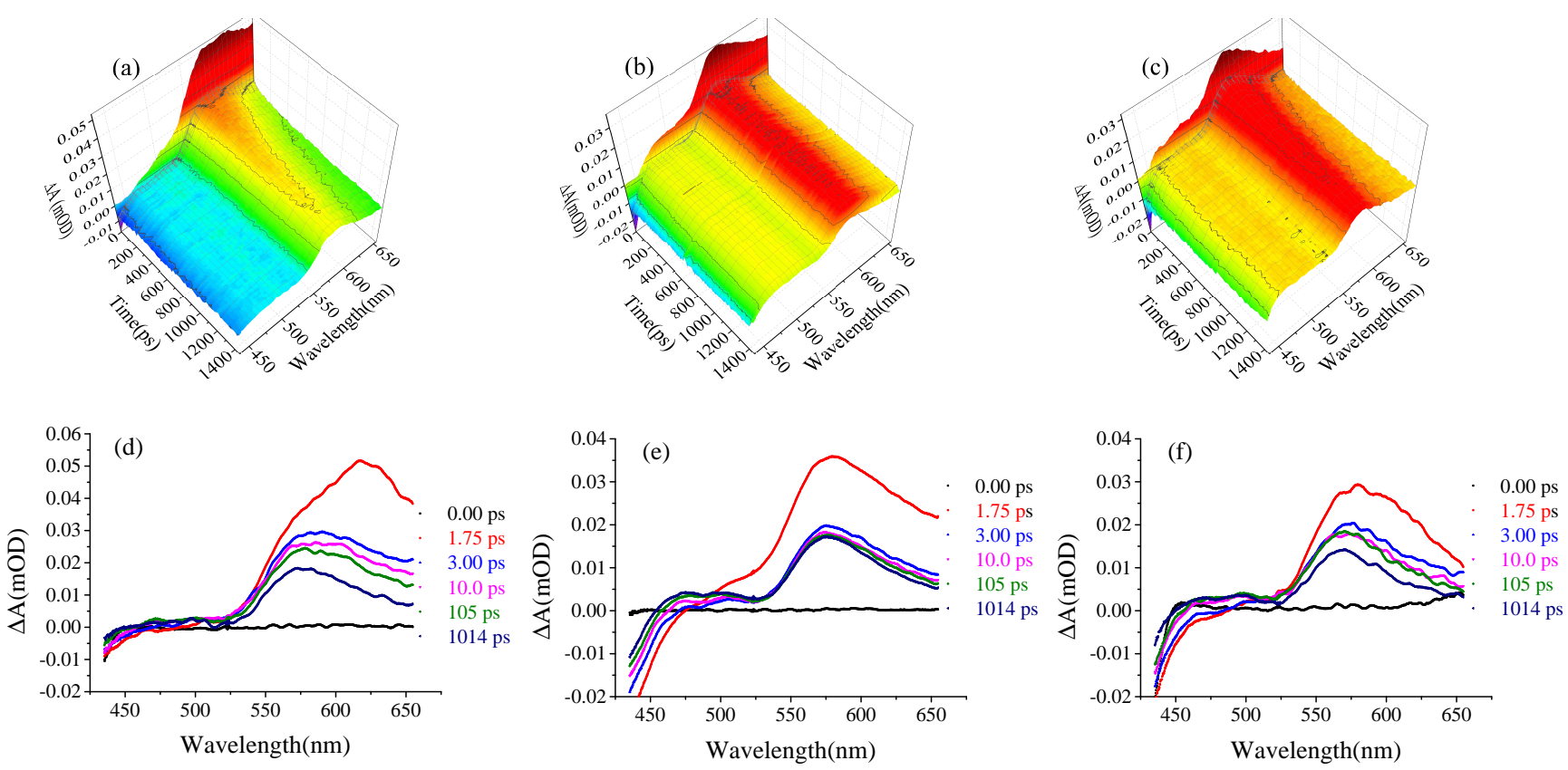

Figure 3: Three dimensional colour maps of the obtained transient absorption data for (a) pristine hematite, (b) $\mathrm{Nb}_{2} \mathrm{O}_{5}{ }^{-}$ hematite and (c) $\mathrm{SnO}_{2}$-hematite samples. Corresponding difference absorption spectra at selected delay times from $t=0$ ps to $t=1014$ ps are shown from (d)-(f)

recombination of electrons and holes as well electron trapping by defect states and/or electronic levels [42]. The first and second lifetimes do not show a strong sample dependency. The third decay lifetimes are in the range of 125-289 ps and we attribute these to recombination of electrons (in the conduction band) and holes. On this timescale we observe that recombination in pristine $\alpha-\mathrm{Fe}_{2} \mathrm{O}_{3}$ is at least a factor of 2 times faster compared with the rates in samples where host materials are used. The reduced rates suggest that electron transfer takes place from $\alpha-\mathrm{Fe}_{2} \mathrm{O}_{3}$ to the under-layer, thereby depleting the available electron density that would otherwise be involved in recombination, consequently slowing down the process. The conduction band minima $\left(\mathrm{CB}_{\text {min }}\right)$ of $\mathrm{Nb}_{2} \mathrm{O}_{5}$ and $\mathrm{SnO}_{2}$ are $0.19 \mathrm{eV}$ and $0.28 \mathrm{eV}$ above that of $\alpha-\mathrm{Fe}_{2} \mathrm{O}_{3}$, respectively [43], thus electron transfer to the under-layers is still possible. The valence band maxima $\left(\mathrm{VB}_{\max }\right)$ of $\mathrm{Nb}_{2} \mathrm{O}_{5}$ and $\mathrm{SnO}_{2}$, on the other hand, are lower than that of hematite and thus hole transfer to the under-layers is highly unlikely. Assuming that excess energy from the pump photons is equally shared between photo-generated lectron-hole pairs, the electrons would be capable of occupying energy levels of up to $0.55 \mathrm{eV}$ above the $\mathrm{CB}_{\text {min }}$, i.e. higher than the $\mathrm{CB}_{\text {min }}$ of both under-layers. Looking at the $\mathrm{CB}_{\text {min }}$ relative positions, we observe that electron transfer is even more favourable to the $\mathrm{Nb}_{2} \mathrm{O}_{5}$ than to the $\mathrm{SnO}_{2}$ under-layer, hence we observe an even slower recombination rate where the $\mathrm{Nb}_{2} \mathrm{O}_{5}$ is used as the under-layer. Interfacial layers suppress back electron transfer from the FTO to $\alpha$ - $\mathrm{Fe}_{2} \mathrm{O}_{3}$. All decay lifetimes obtained from global analysis are summarized in Table 1. 
Table 1: Decay lifetimes for the respective samples obtained from global analysis.

\begin{tabular}{ccccc}
\hline \hline & $\tau_{1}(\mathrm{fs})$ & $\tau_{2}(\mathrm{ps})$ & $\tau_{3}(\mathrm{ps})$ & $\tau_{4}(\mathrm{~ns})$ \\
\hline Prestine hematite & 178 & 1.46 & 125 & 5.1 \\
$\mathrm{SnO}_{2}$-hematite & 134 & 1.55 & 252 & 7.9 \\
$\mathrm{Nb}_{2} \mathrm{O}_{5}$-hematite & 114 & 1.43 & 289 & 8.6 \\
\hline
\end{tabular}

Considering the fourth lifetime, we again observed a faster recombination rate in the pristine $\alpha-\mathrm{Fe}_{2} \mathrm{O}_{3}$ sample compared to the other samples. The fourth decay lifetime is most likely associated with, though not limited to, recombination of electrons transferred back from the FTO. Even though the under-layers suppress back electron flow, they do not completely prohibit this back transfer, hence recombination with these electrons continues to take place once they are transferred to the hematite material. Electrons transferred to the under-layers are also available for back transfer, thus contributing to the electrons that can recombine with valence band holes. In pure hematite where under-layers are not used, this back electron flow is faster, leading to the observed faster recombination. Reported photo-current enhancement following the use of under-layers is therefore attributed to the fact that there is limited recombination due to suppression of electron back flow. Trapping of electrons is also possible by energy levels in the under-layer materials and this in turn possibly slows down the back electron transfer.

Besides photo-current enhancement by suppression of back electron flow from the FTO, under-layers used also lead to diffuse doping of hematite, which consequently leads to higher carrier concentration in semiconductor materials. When hematite is doped with $\mathrm{Sn}$ and $\mathrm{Nb}$, there is substitution of $\mathrm{Fe}^{3+}$ by $\mathrm{Sn}^{4+}$ 44 and $\mathrm{Nb}^{5+}$ [45, 46], respectively. This leads to an increase in the free carrier concentrations, thus also leading to enhancement of photo-current. Under an applied bias in a PEC cell, photo-generated electrons are channelled to a counter electrode, usually a platinum cathode, thus the free carriers created via diffuse doping will not accelerate recombination. This leaves photo-created holes available for water reduction to produce $\mathrm{O}_{2}$ and $\mathrm{H}^{+}$, while reduction of the $\mathrm{H}^{+}$ions to $\mathrm{H}_{2}$ takes place at the platinum cathode.

\subsubsection{Target analysis and recombination models}

To give a better account of the relaxation and recombination processes following photo-excitation, we carried out target analysis with the models shown in Figure 4. The models are identical except for the under-layer in Fig $4 \mathrm{~b}$.

A pump pulse of $3.2 \mathrm{eV}$ creates electron-hole pairs that have excessive energy, thus the electrons occupy levels above the conduction band minimum $\left(\mathrm{CB}_{\text {min }}\right)$ while the holes remain below the valence band maximum $\left(\mathrm{VB}_{\max }\right)$. The processes of electron and hole cooling follows to $\mathrm{CB}_{\min }$ and $\mathrm{VB}_{\max }$ respectively. These processes happens within a typical time-scale of $136-164$ fs. The holes that relax to $\mathrm{VB}_{\max }$ are then available 

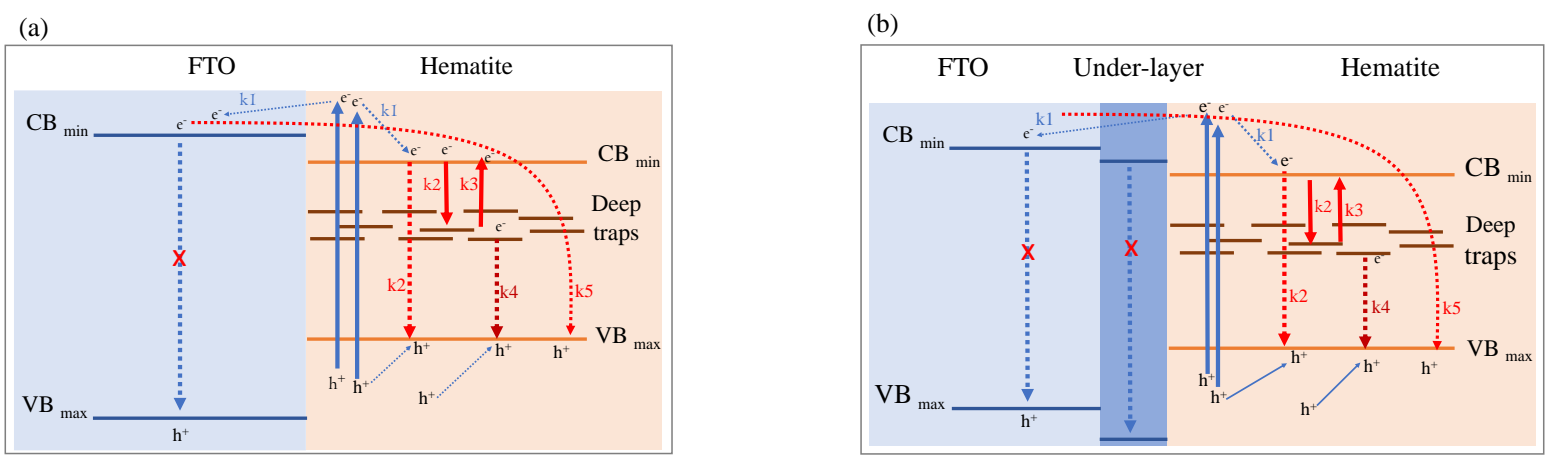

Figure 4: Recombination schemes developed and used in target analysis to obtain associated lifetimes. Blue solid arrows represent the action of the pump pulse, creating electron-hole pairs. The blue dotted arrows represent electron cooling to the conduction band minimum, electron trapping by the FTO, and hole cooling to the valence band maximum. Red solid arrows show electron trapping by the defects or mid gap states while red dotted arrows represent electron-hole recombination and ESA. Kinetic rates used in the analysis are represented by $\mathrm{k}_{n}, n=1-5$ and $\tau_{n}$ for each transition is given by $1 / \mathrm{k}_{n}$. Figure $4 \mathrm{a}$ is a case where no under-layers are used and $4 \mathrm{~b}$ is the model where under-layers are used.

for recombination with electrons. Other than relaxing to $\mathrm{CB}_{\text {min }}$, electrons can also be transferred to the FTO material, whose $\mathrm{CB}_{\text {min }}$ is energetically $0.19 \mathrm{eV}$ above that of hematite, at the same timescale. From $\mathrm{CB}_{\min }$, electrons can either recombine directly with the valence band holes or they can be trapped by impurities and mid-gap states. The two processes occur with a lifetime of 1.15-1.63 ps. The trapped electron recombines with the valence holes with a recombination lifetime of 46.6-77.7 ps. Lastly, recombination of electrons from FTO with holes in the hematite material takes place. Even though in samples where host materials are used this recombination might include transfer to the under-layer and from the under-layer to hematite conduction band before recombination, for simplicity we omit these steps. The effect is, however, noticeable in the lifetimes. In the case where we do not use under-layers, we obtain the time of this recombination as $5.4 \mathrm{~ns}$, while we obtain $8.1 \mathrm{~ns}$ for $\mathrm{SnO}_{2}$ and $9.3 \mathrm{~ns}$ for $\mathrm{Nb}_{2} \mathrm{O}_{5}$ under-layer samples. This shows the effect of under-layers in slowing down recombination, particularly with the electrons that are transferred from the FTO.

\section{Conclusions}

We carried out ultrafast pump-probe spectroscopy on hematite thin films in which $\mathrm{Nb}_{2} \mathrm{O}_{5}$ and $\mathrm{SnO}_{2}$ materials were used as under-layers to suppress electron-hole recombination. From data analysis we show that the use of under-layers does indeed suppress back electron flow from the FTO and thus limits electronhole recombination. We obtained sub-ps decay lifetimes which do not show sample dependency. This was attributed to the fact that these lifetimes correspond to electron and hole cooling to the band edges, and thus no influence is expected from the under-layers. A clear under-layer influence on the recombination timescale is observed on a 100 ps to nanosecond scale where the under-layers are expected to slow down 
back electron flow from the FTO to hematite. We also performed target analysis on our transient absorption data to determine the likely recombination channels and associated timescales. We conclude that the use of under-layers does not completely prohibit back flow of electrons from FTO but rather slows down the process leading eventually to slow recombination rates at a nanosecond scale. A comparative study to show the effect of a wide range of under-layers and over-layers can be carried out to determine which materials are more effective in enhancing hole lifetimes and ultimately PEC performance.

\section{Acknowledgements}

Bursaries from the African Laser Centre (ALC) and from the University of Pretoria (UP Postgraduate Research Support Bursary) are greatly acknowledged. T.P.J.K. acknowledges the Rental Pool Programme of the National Laser Centre and Department of Science and Technology (Grant number LREJA11), and a grant from the Photonics Initiative of South Africa. M.D. acknowledges the National Research Foundation (NRF), South Africa, for financial assistance, NFP (Grant number 88021)

\section{References}

[1] A. Cho, "Energy's tricky tradeoffs," Science, vol. 329, no. 5993, pp. 786-787, 2010.

[2] T. Hisatomi, J. Kubota, and K. Domen, "Recent advances in semiconductors for photocatalytic and photoelectrochemical water splitting," Chemical Society Reviews, vol. 43, no. 22, pp. 7520-7535, 2014.

[3] E. S. Cho, M. J. Kang, and Y. S. Kang, "Enhanced photocurrent density of hematite thin films on FTO substrates: effect of post-annealing temperature," Physical Chemistry Chemical Physics, vol. 17, no. 24 , pp. 16145-16150, 2015.

[4] B. Iandolo, B. Wickman, I. Zorić, and A. Hellman, "The rise of hematite: origin and strategies to reduce the high onset potential for the oxygen evolution reaction," Journal of Materials Chemistry A, vol. 3, no. 33, pp. 16896-16912, 2015.

[5] Z. Huang, Y. Lin, X. Xiang, W. Rodríguez-Córdoba, K. J. McDonald, K. S. Hagen, K.-S. Choi, B. S. Brunschwig, D. G. Musaev, C. L. Hill, et al., "In situ probe of photocarrier dynamics in water-splitting hematite $\left(\alpha-\mathrm{Fe}_{2} \mathrm{O}_{3}\right)$ electrodes," Energy \& Environmental Science, vol. 5, no. 10, pp. 8923-8926, 2012.

[6] R. Milan, S. Cattarin, N. Comisso, C. Baratto, K. Kaunisto, N. Tkachenko, and I. Concina, "Compact hematite buffer layer as a promoter of nanorod photoanode performances," Scientific reports, vol. 6, p. 35049, 2016.

[7] I. Kondofersky, H. K. Dunn, A. Muller, B. Mandlmeier, J. M. Feckl, D. Fattakhova-Rohlfing, C. Scheu, L. M. Peter, and T. Bein, "Electron collection in host-guest nanostructured hematite photoanodes for water splitting: The influence of scaffold doping density," ACS applied materials 83 interfaces, vol. 7, no. 8, pp. 4623-4630, 2015. 
[8] F. Le Formal, K. Sivula, and M. Gratzel, "The transient photocurrent and photovoltage behavior of a hematite photoanode under working conditions and the influence of surface treatments," The Journal of Physical Chemistry C, vol. 116, no. 51, pp. 26707-26720, 2012.

[9] H. Miyake and H. Kozuka, "Photoelectrochemical properties of $\mathrm{Fe}_{2} \mathrm{O}_{3}-\mathrm{Nb}_{2} \mathrm{~N}_{5}$ films prepared by solgel method," The Journal of Physical Chemistry B, vol. 109, no. 38, pp. 17951-17956, 2005.

[10] M. P. Dare-Edwards, J. B. Goodenough, A. Hamnett, and P. R. Trevellick, "Electrochemistry and photoelectrochemistry of iron (iii) oxide," Journal of the Chemical Society, Faraday Transactions 1: Physical Chemistry in Condensed Phases, vol. 79, no. 9, pp. 2027-2041, 1983.

[11] L. Wang, A. Palacios-Padrós, R. Kirchgeorg, A. Tighineanu, and P. Schmuki, "Enhanced photoelectrochemical water splitting efficiency of a hematite-ordered $\mathrm{Sb}$ : $\mathrm{SnO}_{2}$ host-guest system," ChemSusChem, vol. 7, no. 2, pp. 421-424, 2014.

[12] L. Steier, I. Herraiz-Cardona, S. Gimenez, F. Fabregat-Santiago, J. Bisquert, S. D. Tilley, and M. Grätzel, "Understanding the role of underlayers and overlayers in thin film hematite photoanodes," Advanced Functional Materials, vol. 24, no. 48, pp. 7681-7688, 2014.

[13] H. Mulmudi, N. Mathews, X. Dou, L. Xi, S. Pramana, Y. Lam, and S. Mhaisalkar, "Controlled growth of hematite $\left(\alpha-\mathrm{Fe}_{2} \mathrm{O}_{3}\right)$ nanorod array on fluorine doped tin oxide: synthesis and photoelectrochemical properties," Electrochemistry Communications, vol. 13, no. 9, pp. 951-954, 2011.

[14] T. Hisatomi, H. Dotan, M. Stefik, K. Sivula, A. Rothschild, M. Grätzel, and N. Mathews, "Enhancement in the performance of ultrathin hematite photoanode for water splitting by an oxide underlayer," Advanced Materials, vol. 24, no. 20, pp. 2699-2702, 2012.

[15] S. C. Riha, B. M. Klahr, E. C. Tyo, S. Seifert, S. Vajda, M. J. Pellin, T. W. Hamann, and A. B. Martinson, "Atomic layer deposition of a submonolayer catalyst for the enhanced photoelectrochemical performance of water oxidation with hematite," ACS nano, vol. 7, no. 3, pp. 2396-2405, 2013.

[16] S. Shen, P. Guo, D. A. Wheeler, J. Jiang, S. A. Lindley, C. X. Kronawitter, J. Z. Zhang, L. Guo, and S. S. Mao, "Physical and photoelectrochemical properties of Zr-doped hematite nanorod arrays," Nanoscale, vol. 5, no. 20, pp. 9867-9874, 2013.

[17] D. Wang, H. Chen, G. Chang, X. Lin, Y. Zhang, A. Aldalbahi, C. Peng, J. Wang, and C. Fan, "Uniform doping of titanium in hematite nanorods for efficient photoelectrochemical water splitting," ACS applied materials $\&$ interfaces, vol. 7, no. 25, pp. 14072-14078, 2015.

[18] I. Cesar, K. Sivula, A. Kay, R. Zboril, and M. Gratzel, "Influence of feature size, film thickness, and silicon doping on the performance of nanostructured hematite photoanodes for solar water splitting," The Journal of Physical Chemistry C, vol. 113, no. 2, pp. 772-782, 2008. 
[19] N. T. Hahn and C. B. Mullins, "Photoelectrochemical performance of nanostructured Ti-and Sn-doped $\alpha-\mathrm{Fe}_{2} \mathrm{O}_{3}$ photoanodes," Chemistry of Materials, vol. 22, no. 23, pp. 6474-6482, 2010.

[20] V. R. Satsangi, S. Kumari, A. P. Singh, R. Shrivastav, and S. Dass, "Nanostructured hematite for photoelectrochemical generation of hydrogen," International Journal of Hydrogen Energy, vol. 33, no. 1, pp. 312-318, 2008.

[21] N. Beermann, L. Vayssieres, S.-E. Lindquist, and A. Hagfeldt, "Photoelectrochemical studies of oriented nanorod thin films of hematite," Journal of the Electrochemical Society, vol. 147, no. 7, pp. 2456-2461, 2000.

[22] J. A. Glasscock, P. R. Barnes, I. C. Plumb, and N. Savvides, "Enhancement of photoelectrochemical hydrogen production from hematite thin films by the introduction of Ti and Si," The Journal of Physical Chemistry C, vol. 111, no. 44, pp. 16477-16488, 2007.

[23] K. Sivula, F. L. Formal, and M. Gratzel, " $\mathrm{WO}_{3}-\mathrm{fe}_{2} \mathrm{O}_{3}$ photoanodes for water splitting: A host scaffold, guest absorber approach," Chemistry of Materials, vol. 21, no. 13, pp. 2862-2867, 2009.

[24] P. S. Shinde, S. Y. Lee, S. H. Choi, H. H. Lee, J. Ryu, and J. S. Jang, "A synergistic effect of surfactant and $\mathrm{ZrO}_{2}$ underlayer on photocurrent enhancement and cathodic shift of nanoporous $\mathrm{Fe} 2 \mathrm{O} 3$ photoanode," Scientific Reports, vol. 6, p. 32436, 2016.

[25] M. J. Kang and Y. S. Kang, "Ultrathin insulating under-layer with a hematite thin film for enhanced photoelectrochemical (PEC) water splitting activity," Journal of Materials Chemistry A, vol. 3, no. 30, pp. 15723-15728, 2015.

[26] M. Pyeon, M. Wang, Y. Gönüllü, A. Kaouk, S. Jäckle, S. Christiansen, T. Hwang, K. Moon, and S. Mathur, "Design of multi-layered $\mathrm{Tio}_{2}-\mathrm{Fe}_{2} \mathrm{O}_{3}$ photoanodes for photoelectrochemical water splitting: patterning effects on photocurrent density," MRS Communications, vol. 6, no. 4, pp. 442-448, 2016.

[27] T. Hisatomi, J. Brillet, M. Cornuz, F. Le Formal, N. Tétreault, K. Sivula, and M. Grätzel, "A $\mathrm{Ga}_{2} \mathrm{O}_{3}$ underlayer as an isomorphic template for ultrathin hematite films toward efficient photoelectrochemical water splitting," Faraday discussions, vol. 155, pp. 223-232, 2012.

[28] K. Maabonga, Y. Hu, A. Braun, A. G. Machatine, and M. Dialeb, "Influence of anodization time on the surface modifications on a- $\mathrm{Fe}_{2} \mathrm{O}_{3}$ photoanode upon anodization," Journal of Materials Research, vol. 31, no. 11, pp. 1580-1587, 2016.

[29] J. Snellenburg, S. Laptenok, R. Seger, K. Mullen, and I. Van Stokkum, "Glotaran: a java-based graphical user interface for the R package TIMP," Journal of Statistical Software, vol. 49, no. 3, 2012.

[30] M. Rebien, W. Henrion, M. Hong, J. Mannaerts, and M. Fleischer, "Optical properties of gallium oxide thin films," Applied physics letters, vol. 81, no. 2, pp. 250-252, 2002. 
[31] S. S. Kumar, E. Rubio, M. Noor-A-Alam, G. Martinez, S. Manandhar, V. Shutthanandan, S. Thevuthasan, and C. Ramana, "Structure, morphology, and optical properties of amorphous and nanocrystalline gallium oxide thin films," The Journal of Physical Chemistry C, vol. 117, no. 8, pp. 4194-4200, 2013.

[32] F. Gu, S. F. Wang, M. K. Lü, G. J. Zhou, D. Xu, and D. R. Yuan, "Photoluminescence properties of $\mathrm{SnO}_{2}$ nanoparticles synthesized by sol- gel method," The Journal of Physical Chemistry B, vol. 108, no. 24 , pp. 8119-8123, 2004.

[33] V. Agekyan, "Spectroscopic properties of semiconductor crystals with direct forbidden energy gap," physica status solidi (a), vol. 43, no. 1, pp. 11-42, 1977.

[34] R. Summitt, J. A. Marley, and N. F. Borrelli, "The ultraviolet absorption edge of stannic oxide $\left(\mathrm{SnO}_{2}\right)$," Journal of Physics and Chemistry of Solids, vol. 25, no. 12, pp. 1465-1469, 1964.

[35] D. Hayes, R. G. Hadt, J. D. Emery, A. A. Cordones, A. B. Martinson, M. L. Shelby, K. A. Fransted, P. D. Dahlberg, J. Hong, X. Zhang, et al., "Electronic and nuclear contributions to time-resolved optical and X-ray absorption spectra of hematite and insights into photoelectrochemical performance," Energy \& Environmental Science, vol. 9, no. 12, pp. 3754-3769, 2016.

[36] P. Liao and E. A. Carter, "Optical excitations in hematite $\left(\alpha-\mathrm{Fe}_{2} \mathrm{O}_{3}\right)$ via embedded cluster models: a CASPT2 study," The Journal of Physical Chemistry C, vol. 115, no. 42, pp. 20795-20805, 2011.

[37] D. A. Wheeler, G. Wang, Y. Ling, Y. Li, and J. Z. Zhang, "Nanostructured hematite: synthesis, characterization, charge carrier dynamics, and photoelectrochemical properties," Energy $\&$ Environmental Science, vol. 5, no. 5, pp. 6682-6702, 2012.

[38] L. A. Marusak, R. Messier, and W. B. White, "Optical absorption spectrum of hematite, $\alpha f e 2 o 3$ near ir to uv," Journal of Physics and Chemistry of Solids, vol. 41, no. 9, pp. 981-984, 1980.

[39] J. Tossell, D. Vaughan, and K. Johnson, "Electronic-structure of rutile, wustite, and hematite from molecular-orbital calculations," American Mineralogist, vol. 59, no. 3-4, pp. 319-334, 1974.

[40] S. R. Pendlebury, M. Barroso, A. J. Cowan, K. Sivula, J. Tang, M. Grätzel, D. Klug, and J. R. Durrant, "Dynamics of photogenerated holes in nanocrystalline $\alpha-\mathrm{Fe}_{2} \mathrm{O}_{3}$ electrodes for water oxidation probed by transient absorption spectroscopy," Chemical Communications, vol. 47, no. 2, pp. 716-718, 2011.

[41] I. H. van Stokkum, D. S. Larsen, and R. van Grondelle, "Global and target analysis of time-resolved spectra," Biochimica et Biophysica Acta (BBA)-Bioenergetics, vol. 1657, no. 2, pp. 82-104, 2004.

[42] A. G. Joly, J. R. Williams, S. A. Chambers, G. Xiong, W. P. Hess, and D. M. Laman, "Carrier dynamics in $\alpha-\mathrm{Fe}_{2} \mathrm{O}_{3}$ (0001) thin films and single crystals probed by femtosecond transient absorption and reflectivity," Journal of applied physics, vol. 99, no. 5, p. 053521, 2006. 
[43] Y. Xu and M. A. Schoonen, "The absolute energy positions of conduction and valence bands of selected semiconducting minerals," American Mineralogist, vol. 85, no. 3-4, pp. 543-556, 2000.

[44] Y. Ling, G. Wang, D. A. Wheeler, J. Z. Zhang, and Y. Li, "Sn-doped hematite nanostructures for photoelectrochemical water splitting," Nano letters, vol. 11, no. 5, pp. 2119-2125, 2011.

[45] A. C. Silva, D. Q. Oliveira, L. C. Oliveira, A. S. Anastacio, T. C. Ramalho, J. H. Lopes, H. W. Carvalho, and C. E. R. Torres, "Nb-containing hematites $\mathrm{Fe}_{2-X} \mathrm{Nb}_{X} \mathrm{O}_{3}$ : the role of $\mathrm{nb}^{5+}$ on the reactivity in presence of the $\mathrm{H}_{2} \mathrm{O}_{3}$ or ultraviolet light," Applied Catalysis A: General, vol. 357, no. 1, pp. 79-84, 2009.

[46] Y. Fu, C.-L. Dong, W.-Y. Lee, J. Chen, P. Guo, L. Zhao, and S. Shen, "Nb-doped hematite nanorods for efficient solar water splitting: Electronic structure evolution versus morphology alteration," ChemNanoMat, vol. 2, no. 7, pp. 704-711, 2016. 